\title{
The effect of oxalic acid applied by sublimation on honey bee colony fitness: a comparison with amitraz
}

\author{
Ivana Papežíková, Miroslava Palíková, Stanislav Navrátil, Radka Heumannová, \\ Michael Fronc
}

University of Veterinary and Pharmaceutical Sciences Brno, Faculty of Veterinary Hygiene and Ecology, Department of Ecology and Diseases of Game, Fish and Bees, Brno, Czech Republic

\author{
Received March 14, 2016 \\ Accepted August 31, 2016
}

\begin{abstract}
Oxalic acid is one of the organic acids used for controlling Varroa destructor, a mite parasitizing the honey bee (Apis mellifera). The aim of this work was to examine the effect of oxalic acid applied by sublimation on honey bee colony fitness, and to compare it with the effect of amitraz, a routinely used synthetic acaricide. Bee colonies of equal strength were randomly divided into two groups. In December 2014, one group was treated with amitraz in the form of aerosol, and the second group was treated with oxalic acid applied by sublimation. The colonies were monitored over winter. Dead bees found at the bottom of the hive were counted regularly and examined microscopically for infection with Nosema sp. (Microsporidia). At the end of March 2015, living foragers from each hive were sampled and individually examined for Nosema sp. infection. Colony strength was evaluated at the beginning of April. No adverse effect of oxalic acid on colony strength was observed despite the fact that the total number of dead bees was non-significantly higher in the oxalic acid-treated group. Examination of dead bees for Nosema infection did not reveal significant differences in spore numbers between the experimental groups. There was a substantial difference in living individuals, however, with a significantly higher amount of spores per bee found in the amitraz-treated colonies compared to the oxalic acid-treated colonies. Compared to amitraz, oxalic acid applied by sublimation showed no adverse effects on bee colony fitness or on successful overwintering.
\end{abstract}

Apis mellifera, mite control, Nosema sp.

The most destructive disease of the western honey bee (Apis mellifera) is infestation by the parasitic mite Varroa destructor (E1lis et al. 2010; Le Conte et al. 2010; Potts et al. 2010). Without treatment, bee colonies collapse within 2-3 years; hence it is necessary to control varroosis throughout the year, and to maintain as low level of infestation as possible (Rosenkranz et al. 2010; Dooremalen et al. 2012). Treatment during autumn/ winter is a very effective form of intervention as there is usually no brood in the colony. All mites are present on adult bees and cannot escape the treatment being capped in the brood cells. When treatment is successful, bees can enter the next season with almost zero mite infestation.

In the Czech Republic, there are several registered medications designed for the Varroa mite control based on 1) synthetic acaricides - amitraz (Varidol 125, VÚVč Dol, Czech Republic), and tau-fluvalinate (M-1 AER, MP-10 FUM and Gabon PF 90, all produced by VÚVč Dol, Czech Republic); or on 2) natural compounds - formic acid (Formidol 40 and Formidol 81, both produced by VÚVč Dol, Czech Republic), and thymol (Apiguard 25\% Gel, Vita Europe, UK and Thymovar $15 \mathrm{~g}$, Andermatt BioVet GmbH, Lörrach, Germany). Increasing problems with mite resistance to synthetic acaricides has prompted a search for alternative means of treatment. At present, however, there are no registered natural alternatives to synthetic acaricides in the Czech Republic that can be used for varroosis

Address for correspondence:

MVDr. Ivana Papežíková, Ph.D.

Department of Ecology and Diseases of Game, Fish and Bees

Faculty of Veterinary Hygiene and Ecology

University of Veterinary and Pharmaceutical Sciences Brno

Palackého tř. 1946/1, 61242 Brno, Czech Republic

Phone: +420 541562661

E-mail: papezikovai@vfu.cz

http://actavet.vfu.cz/ 
control during the winter broodless period. Oxalic acid can be used for this purpose (Aliano et al. 2009). It is applied by either trickling or sublimation, using an electrically heated pan (Rademacher and Harz 2006). Most authors describe a $>90 \%$ acaricidal effect following application by sublimation (reviewed by Rademacher and Harz 2006). Most work concerning oxalic acid to date has been focused on its acaricidal effect (Akyol 2009; Girişgin and Aydin 2010; Gregorc and Planinc 2001; Gregorc and Planinc 2004; Rademacher and Harz 2006; Skerl et al. 2011; Toufailia et al. 2015); fewer studies examine the effect of this treatment on honey bee health (Rademacher and Harz 2006; Schneider et al. 2012; Toomemaa et al. 2010; Toufailia et al. 2015).

The aim of this pilot field study was to examine the effect of oxalic acid on honey bee colony fitness and to compare it with the effects of amitraz, a routinely used synthetic acaricide. In addition, we examined the effect of oxalic acid on prevalence and intensity of infection by the microsporidia Nosema sp. As formic acid, which is used for spring/ summer treatment of varroosis, has been shown to decrease build-up of Nosema sp. spores (Underwood et al. 2009), we hypothesised that oxalic acid could have a similar effect.

\section{Materials and Methods}

In October 2014, eleven bee colonies of equal strength (each colony occupying three Langstroth hive bodies $159 \mathrm{~mm}$ high) were randomly divided into two groups. During autumn, both groups were treated twice against the mite Varroa destructor using amitraz, (Varidol Fum, VúVč Dol, Czech Republic) applied by fumigation as directed by the Czech State Veterinary Administration. At the end of December, one group $(n=6)$ was treated with amitraz in the form of aerosol according to the manufacturer's protocol, while the second group $(\mathrm{n}=5)$ was treated with oxalic acid (oxalic acid dihydrate, Verkon, Czech Republic; $1 \mathrm{~g}$ per hive body), applied by sublimation (outside temperature at time of application $=+5^{\circ} \mathrm{C}$ ). An electric pan (Varrox, BioVet, Switzerland) containing oxalic acid was placed into the beehive through the hive entrance. The hive entrance was then closed tightly and the pan connected to a $12 \mathrm{~V}$ battery. After $2.5 \mathrm{~min}$, the pan was disconnected and left in the hive for further $2 \mathrm{~min}$, whereupon the hive was closed for $10 \mathrm{~min}$.

Dead bees found at the bottom of the beehive during overwintering were regularly sampled (at the beginning of February, end of February, beginning of March, and end of March 2015), and counted.

\section{Examination for Nosema sp. microsporidia infection}

The abdomens of fifty dead bees from each sample were homogenised in $5 \mathrm{ml}$ of tap water and filtered through a mule, whereupon the final volume of the homogenate was recorded. Present Nosema spores were identified microscopically as Nosema ceranae. However, weak simultaneous infection by Nosema apis could not be excluded, as small amount of Nosema apis spores potentially present in the samples could be missed during microscopical examination. Therefore, we considered the infection as infection with Nosema sp. Spores were counted using a haemocytometer and the number of spores per bee was calculated. Living foragers $(\mathrm{n}=34$ in the amitraz-treated group and $\mathrm{n}=37$ in the oxalic acid-treated group) were sampled and individually examined for Nosema sp. infection at the end of March, when the outside temperature increased and bees started to fly out of the hive. The percentage of infected and non-infected bees was estimated and spores were counted in infected individuals. The mean spore number per bee was calculated for each experimental group.

Evaluation of colony strength

At the beginning of April 2015 (outside temperature $=+15^{\circ} \mathrm{C}$ ), colony strength was evaluated by counting the number of hive bodies occupied. Colonies occupying one hive body were classified as weak (coefficient 1), two hive bodies as medium (coefficient 2) and three hive bodies as strong (coefficient 3 ). Coefficients assigned to particular colonies were summed and the mean value for each group calculated.

Statistical analysis

Data are reported as mean \pm standard error of the mean. Data were evaluated using Student's $t$-test with significance assumed at $P<0.05$.

\section{Results}

None of the experimental colonies died during overwintering. No significant difference in the numbers of dead bees found at the bottom of the hive was found between the experimental groups. Just prior to the fourth sampling, the outside temperature increased 


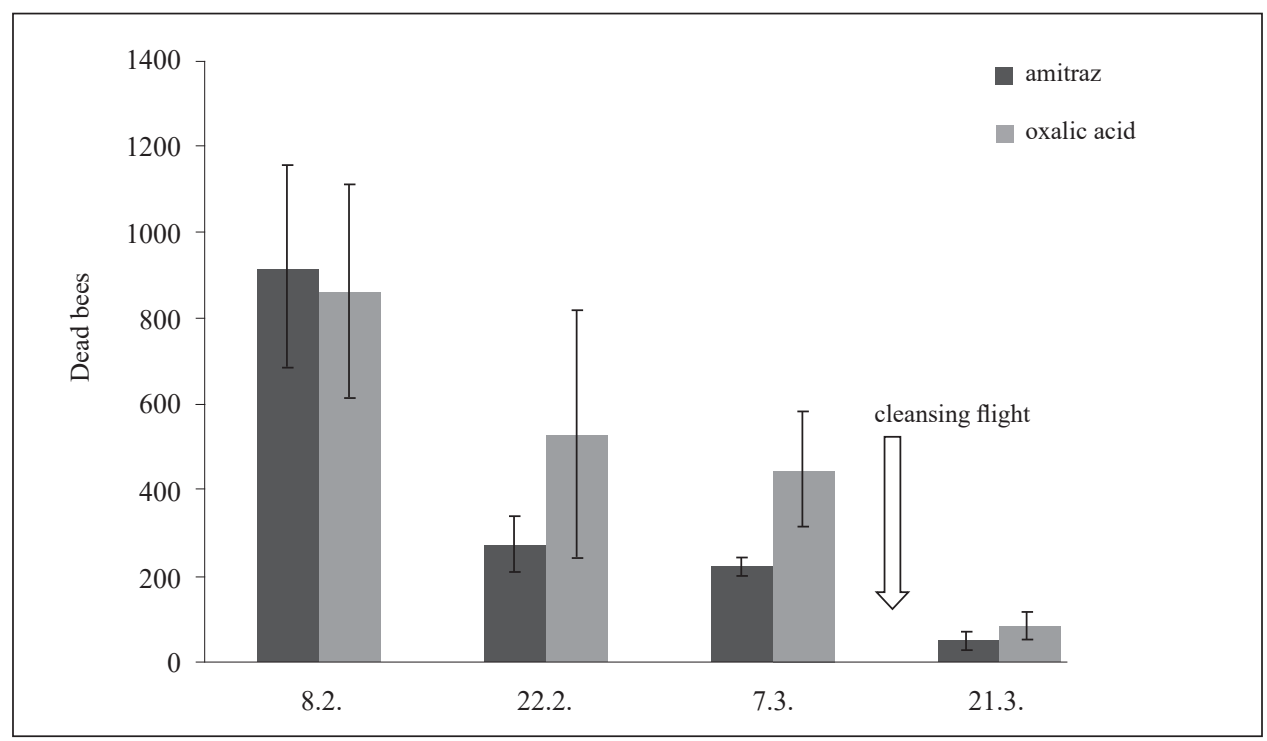

Fig. 1. Numbers of dead honey bees found on the bottom of each hive. Data represent mean \pm standard error.

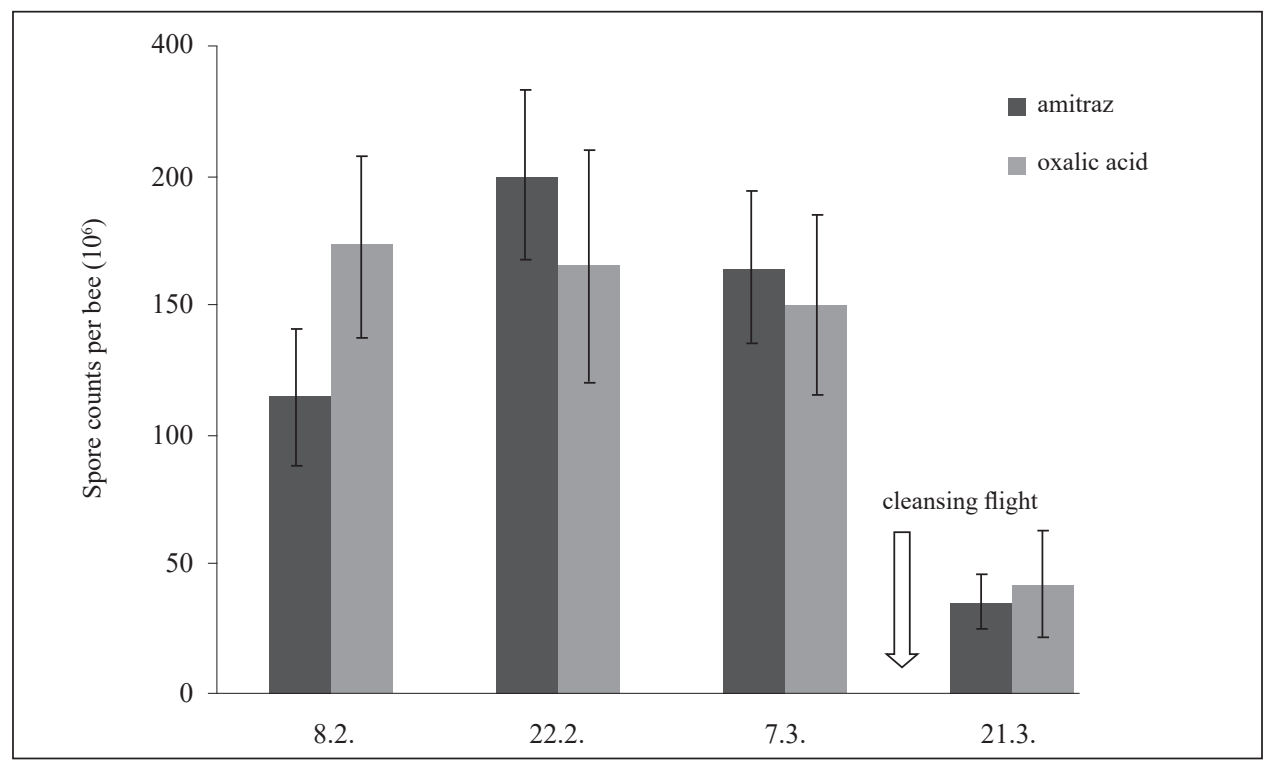

Fig. 2. Spore counts per bee (expressed in millions). Collective examination of dead honey bees found at the bottom of each hive. Data represent mean \pm standard error.

and bees started to leave the hive to forage, removing debris and dead bees from the bottom of the hive. As a result, the number of dead bees was very low at this time and almost equal in both groups (Fig. 1). In the oxalic acid-treated group, the total number of dead bees during overwintering was higher $(1926 \pm 661)$ compared to the amitraz-treated group 
(1472 \pm 331$)$, but not significantly. Evaluation of colony strength in spring revealed that the oxalic acid-treated colonies survived winter in better condition than colonies treated with amitraz (mean coefficient $2.8 \pm 0.18$ and $2.0 \pm 0.24$, respectively).

Examination of dead bees for Nosema sp. infection indicated 100\% prevalence of the disease at the apiary. Examination of dead bees found at the beehive bottom did not reveal any difference in spore numbers between the experimental groups (Fig. 2). However, substantial difference was found in living foragers. In amitraz-treated colonies, $38 \%$ of foragers were infected while only $6 \%$ of foragers were positive for Nosema sp. in the oxalic acid-treated colonies. Correspondingly, the mean spore number per bee was significantly lower in the oxalic acid-treated group (Fig. 3).

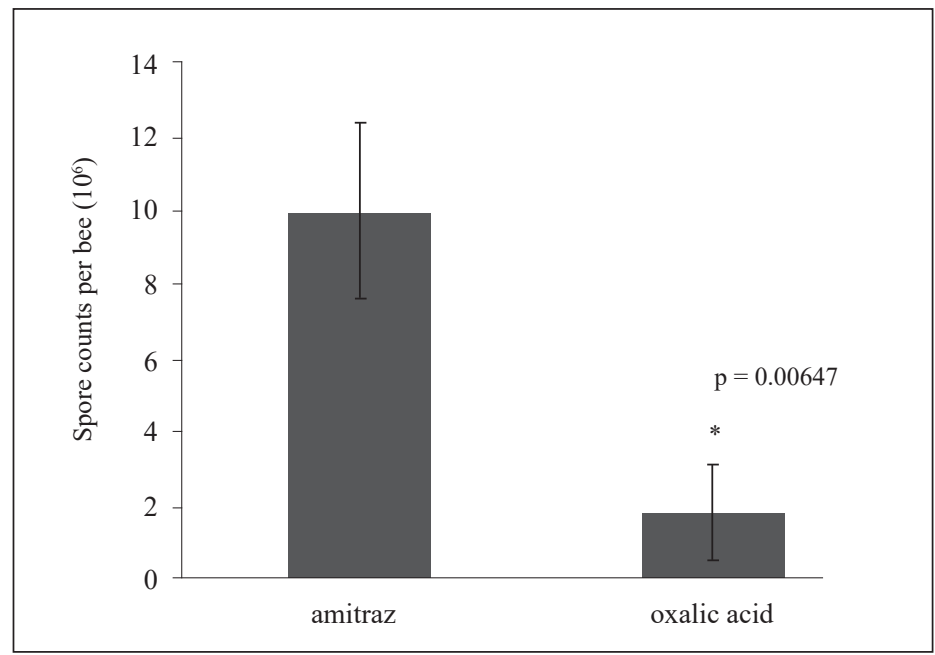

Fig. 3. Mean number of Nosema sp. spores in living foragers sampled on the $26^{\text {th }}$ March 2015 at the hive entrance.

\section{Discussion}

It has previously been shown that oxalic acid is a highly effective treatment against the Varroa mite (Rademacher and Harz 2006; Toomemaa et al. 2010; Skerl et al. 2011), with low acute toxicity for bees at doses commonly used for varroosis control (Aliano et al. 2006; Rademacher and Harz 2006). In this small field study, we examined the long-term effect of such treatment on honey bee colonies. Our results showed that a higher number of workers died during overwintering in the oxalic acid-treated colonies. It should be noted, however, that Nosema sp.-infected colonies were used in this study, as it was thought that oxalic acid would be an effective treatment against the infection. Since there was no significant difference between the experimental groups regarding spore numbers on dead bees during overwintering, it is likely that Nosema sp.-infected bees died when the microsporidia completely destroyed their midgut epithelium, with spore numbers reaching similar maximum values in most dead individuals. Thus, individual examination of living foragers was performed in the spring to obtain more accurate information on the disease prevalence and intensity. Lower rate of infection in the oxalic acid-treated group and lower mean count of spores per examined bee is in accordance with the results of Nanetti et al. (2015), who used oxalic acid applied by trickling in the form of sugar syrup in Nosema 
ceranae-infected colonies. They show that oxalic acid-treated colonies overwintered in a better condition than colonies treated with sugar syrup only and the number of Nosema ceranae spores in living individuals was significantly reduced. The lower intensity of infection in the oxalic acid-treated colonies could have several possible explanations. One could be a devitalising effect of oxalic acid on Nosema sp. spores; however, no data on this subject are available so far. A further possibility is the effect of combined exposure to Nosema sp. and oxalic acid. Numerous studies have shown that the life-span of bees is negatively influenced by multiple interacting factors, such as disease, poor nutritional status and/or chemicals (Cornman et al. 2012; Goulson et al. 2015). Although oxalic acid has been shown to have low acute toxicity for honey bees, a slight negative effect on the lifespan was described by Schneider et al. (2012). Thus, it cannot be excluded that combined exposure to oxalic acid and Nosema infection decreases the life-span of honey bees, and that the infected bees die and fall to the bottom of the hive instead of spreading the infection in the colony. Although the total number of dead bees found during the overwintering period was higher in the oxalic acid-treated colonies, this group was found to be stronger after overwintering than the amitraz-treated group. This apparent contradiction could be explained by the fact that only bees that died inside the hive were included in the study. When outside temperatures rise in spring, bees start to leave the hive to forage; hence high numbers of them die outside the hive, especially if they are weakened by the disease. The dying of bees outside the hive is an important part of social immunity and is known to be associated with variety of diseases including infection with Nosema sp. (Botías et al. 2013). It is plausible, therefore, that more bees from colonies with a higher prevalence of nosematosis died outside the hive, leading to the lowered colony strength found at the beginning of April. This assumption (Nosema sp.-infected individuals dying outside the hive) is supported by the low spore numbers per bee found on dead bees following the rise in temperature and the subsequent cleansing flight ( $4^{\text {th }}$ sampling).

Based on our results (using Nosema-infected colonies), it can be concluded that oxalic acid applied by sublimation had no adverse effect on fitness and successful overwintering of the experimental colonies. The question remains, however, as to the effect of sublimated oxalic acid on honey bees uninfected with Nosema. Also the potential association between oxalic acid application and lower prevalence of nosematosis in examined foragers remains to be elucidated by further work.

\section{Acknowledgement}

This work was supported by the Internal Grant Agency of the University of Veterinary and Pharmaceutical Sciences Brno, Project No. 231/2015/FVHE. The authors also would like to thank Dr. Kevin Roche for his linguistic assistance.

\section{References}

Aliano NP, Ellis MD, Siegfried BD 2006: Acute contact toxicity of oxalic acid to Varroa destructor (Acari: Varroidae) and their Apis mellifera (Hymenoptera: Apidae) hosts in laboratory bioassays. J Econ Entomol 99: 1579-1582

Aliano NP, Ellis MD 2009: Oxalic acid: a prospective tool for reducing Varroa mite populations in package bees. Exp Appl Acarol 48: 303-309

Botías C, Martín-Hernández R, Barrios L, Meana Aránzazu, Higes M 2013: Nosema spp. infection and its negative effects on honey bees (Apis mellifera iberiensis) at the colony level. Vet Res 44: 25

Le Conte Y, Ellis M, Ritter W 2010: Varroa mites and honey bee health: can Varroa explain part of the colony losses? Apidologie 41: 353-363

Cornman RS, Tarpy DR, Chen Y, Jeffreys L, Lopez D, Pettis JS, van Engelsdorp D 2012: Pathogen webs in collapsing honey bee colonies. PLoS ONE 7: e43562

van Dooremalen C, Gerritsen L, Cornelissen B, van der Steen JJM, van Langevelde F, Blacquière T 2012: Winter survival of individual honey bees and honey bee colonies depends on level of Varroa destructor infestation. PLoS ONE 7: e36285 
Doublet V, Labarussias M, de Miranda JR, Moritz RFA, Paxton RJ 2014: Bees under stress: sublethal doses of a neonicotinoid pesticide and pathogens interact to elevate honey bee mortality across the life cycle. Environ Microbiol 17: 969-983

Ellis JD, Evans JD, Pettis J 2010: Colony losses, managed colony population decline, and colony collapse disorder in the United States. J Apic Res 49: 134-136

Goulson D, Nicholls E, Botias C, Rotheray EL 2015: Bee declines driven by combined stress from parasites, pesticides and lack of flowers. Science 347: 1-9

Nanetti A, Rodriguez-García C, Meana A, Martín-Hernández R, Higes M 2015: Effect of oxalic acid on Nosema ceranae infection. Res Vet Sci 102: 167-172

Potts SG, Biesmeijer JC, Kremen C, Neumann P, Schweiger O, Kunin WE 2010: Global pollinator declines: trends, impacts and drivers. Trends Ecol Evol 25: 345-353

Rademacher E, Harz M 2006: Oxalic acid for the control of varroosis in honey bee colonies: a review. Apidologie 37: 98-120

Rosenkranz P, Aumeier P, Ziegelmann B 2010: Biology and control of Varroa destructor. J Invertebr Pathol 103: S96-S119

Skerl MIS, Nakrst M, Zvokejl L, Gregorc A 2011: The acaricidal effect of flumethrin, oxalic acid and amitraz against Varroa destructor in honey bee (Apis mellifera carnica) colonies. Acta Vet Brno 80: 51-56

Schneider S, Eisenhardt D, Rademacher E 2012: Sublethal effects of oxalic acid on Apis mellifera (Hymenoptera: Apidae): changes in behaviour and longevity. Apidologie 43: 218-225

Toomemaa K, Martin AJ, Williams IH 2010: The effect of different concentrations of oxalic acid in aequous and sucrose solution on Varroa mites and honey bees. Apidologie 41: 643-653

Underwood RM, Currie RW 2009: Indoor winter fumigation with formic acid for control of Acarapis woodi (Acari: Tarsonemidae) and Nosema disease, Nosema sp. J Econ Entomol 102: 1729-1736 